\title{
Anthocyanins Prevent Colorectal Cancer Development in a Mouse Model
}

\author{
Elisabeth Lippert ${ }^{\mathrm{a}}$ Petra Ruemmele ${ }^{\mathrm{b}}$ Florian Obermeier ${ }^{\mathrm{a}}$ Stefan Goelder ${ }^{\mathrm{c}}$ \\ Claudia Kunst $^{\mathrm{a}}$ Gerhard Rogler $^{\mathrm{d}}$ Nadja Dunger $^{\mathrm{a}}$ Helmut Messmann $^{\mathrm{c}}$ \\ Arndt Hartmann ${ }^{b}$ Esther Endlicher ${ }^{a}$ \\ ${ }^{a}$ Department of Internal Medicine I, University Hospital Regensburg, Regensburg, ${ }^{b}$ Institute for Pathology, \\ University Hospital of Erlangen, Erlangen, and ' Internal Medicine III, Klinikum Augsburg, Augsburg, Germany; \\ ${ }^{\mathrm{d}}$ Division of Gastroenterology and Hepatology, University Hospital Zurich, Zurich, Switzerland
}

\section{Keywords \\ Anthocyanin · Colorectal cancer · Inflammation . Endoscopy · Administration of azoxymethan and dextran sodium sulfate model}

\begin{abstract}
Background: Colorectal cancer is the main leading cause of cancer-related deaths worldwide. Present data suggest that plant-derived anthocyanins have anti-inflammatory and chemopreventive properties. This study was aimed at evaluating the effect of an anthocyanin-rich extract from bilberries on colorectal tumour development and growth in the administration of azoxymethan (AOM)/dextran sodium sulfate (DSS) mouse model. Methods: Colonic carcinogenesis was induced by AOM and DSS 3 or $5 \%$, respectively, in 50 female Balb/c mice. Mice received either normal food (controls) or a diet containing either 10 or $1 \%$ anthocyanin-rich bilberry extract. Colonoscopy took place at week 4 and 9 after initiation of carcinogenesis. After termination at week 9 , colon samples were analysed macroscopically and microscopically. Results: Mice receiving $10 \%$ anthocyanins showed significantly $(p<0.004)$ less reduced colon length $(12.1 \mathrm{~cm}[8.5-14.4 \mathrm{~cm}])$ as compared to controls (11.2 cm [9.8-12.3]) indicating less inflammation. Mice fed with $10 \%$ anthocyanin-rich extract revealed significantly less mean tumour numbers $(n=1.2)$ compared to control
\end{abstract}

\section{KARGER}

(C) 2017 S. Karger AG, Basel

E-Mail karger@karger.com

www.karger.com/dig $(n=14)$ and anthocyanin 1\% treated mice $(n=10.6, p<$ 0.001 ). Conclusion: Anthocyanins prevented the formation and growth of colorectal cancer in AOM/DSS-treated Balb/c mice. Further studies should investigate the mechanisms of how anthocyanins influence the development of colorectal cancer.

(c) 2017 S. Karger AG, Basel

\section{Introduction}

Colorectal cancer is the second most common cancer in Europe and one of the main leading cause of cancerrelated deaths worldwide $[1,2]$. In 2012, 471,240 new CRC cases were diagnosed in Europe with a calculated incidence rate of $12.7 \%$, leading to 228,275 deaths from CRC in the same time and area [3].

Despite efforts for early diagnosis and new therapeutic approaches, there is an urgent need for preventive measures and therapies in high-risk populations.

Regular physical activity, weight reduction for overweight persons and smoking cessation are recommended after a detailed review of the literature for the prevention of CRC [4]. Although a specific diet recommendation is not given, current knowledge suggests that a high consumption of fruit and vegetable is associated with a reduced risk of colorectal cancer [5-7]. 
Anthocyanins are naturally occurring flavonoids, which are responsible for the red, blue and purple colours of numerous fruits and vegetables. Present data demonstrate that anthocyanins play a role in chemoprevention. Anthocyanins carry different glucosides such as glucose, galactose, arabinose and others. Deglycosylated anthocyanins are called anthocyanidins. Depending on their skeleton, there are also different types of anthocyanidin, that is, delphinidin, petunidin and cyanidin. The phenolic structure of anthocyanins is responsible for their antioxidative activity, mainly due to their ability to scavenge reactive oxygen species [8]. Anthocyanins are also involved in the cell cycle, mainly regulatory proteins such as $\mathrm{p} 53$, which can additionally explain the anti-proliferative effect. In vitro studies confirm inhibitory effects on proliferation, angiogenesis and induction of apoptosis in several carcinoma cell lines (HT-29, CaCo-2 and HCT 116) [9-12]. Furthermore, anthocyanins exhibited anti-inflammatory activity due to the inhibition of pro-inflammatory proteins such as nuclear factor- $\kappa \mathrm{B}(\mathrm{NF}-\kappa \mathrm{B})$ and COX-2 in multiple cell types in vitro [13].

In vivo studies using the APC ( $\mathrm{min}$ ) mouse model and the administration of azoxymethan (AOM)-induced model of colon cancer in F344 rats demonstrated reduced development of adenomas and cancer when anthocyanins were applied [14-16].

This study was aimed at establishing murine endoscopy in an AOM- and dextran sodium sulfate (DSS)-induced model of colorectal cancer and in evaluating the effect of anthocyanins on tumour development.

\section{Methods}

\section{Animal Studies}

Female Balb/c mice weighing 20-22 g (Charles River, Germany) were used for the experiments and housed under conventional animal facility conditions. Animals obtained food and water ad libitum. The animal studies were approved by the local Institutional Review Board.

Mice were fed with normal food supplemented with 1 or $10 \%$ anthocyanin-extract, respectively (Symrise, Germany). Control group received normal food.

Two weeks before the induction of experimental colitis, this diet was started and given for the complete duration of the experiment.

Carcinogenesis was induced by one-time injection of $10 \mu \mathrm{g}$ AOM per g mouse i.p.. After 7 days, acute colitis was induced by giving 3 and 5\% DSS in drinking water (MP Biomedicals, Illkirch, France) for 7 days. For induction of chronic colitis, mice received 2 cycles of 3 or $5 \%$ DSS for 7 days interrupted by a period of 7 days with normal drinking water.

We evaluated mice data (colonic length), macroscopic and microscopic findings (tumour size, number and localisation of tumours).

\section{Colonoscopy}

Colonoscopy was performed at weeks 4 and 9 after the initiation of the experiment. Mice were anaesthetised using intraperitoneal injection of xylazin hydrochloride (Bayer, Germany).

For endoscopic evaluation, the "Coloview-system" (Karl Storz, Tuttlingen, Germany) was used [17]. It consisted of a miniature endoscope (1.9 mm outer diameter), a triple chip camera and xenon light. Inflation of the mouse colon was achieved with warm water. Biopsies were taken for histological analysis using a flexible biopsy forceps with a diameter of 3 Fr.

After the second endoscopy, mice were sacrificed as described previously [18]. Colon lengths were evaluated as a sign of inflammation. The overall number of tumours were counted and scored as follows: $0=$ no sign of tumour, $1=$ small, but detectable tumour, 2 = tumour growth in up to half of the colon circumference, 3 = tumours larger than half of the colon circumference.

\section{Assessment of Histology}

Besides taking biopsies in living mice, the distal third of the colon was removed after termination and used for histological analysis as described before [19]. Cross-sections of the colon were fixed in $10 \%$ buffered formalin and stained with haematoxylin-eosin. Dysplastic proliferation of glandular epithelium on microscopic cross-sections of the colon was diagnosed and graded by an experienced pathologist (P.R.) as low-grade or high-grade dysplasia (LG-IEN/HG-IEN).

\section{Statistics}

Colon lengths are given as mean and range. Statistical analyses were performed using the Student $t$ test and Mann-Whitney rank sum test. Statistically significant differences were accepted when $p<0.05$.

\section{Results}

Histology Reveals Colorectal Tumour Development in AOM DSS Mouse Model

Sections of the colon were analysed histologically. Histology confirmed the development of intraepithelial neoplasia with low-grade or high-grade dysplasia (LG-IEN/ HG-IEN) in mice treated with AOM/DSS as flat lesions or as dysplasia-associated lesion or mass as observed in human (Fig. 1a, b). Dysplasia-associated invasive carcinoma was not observed.

\section{Anthocyanin-Treated Mice Develop Less Colonic Inflammation}

The reduction of colon length caused by inflammation is a known feature of DSS colitis [20]. Mice receiving 10\% anthocyanins showed significantly $(p<0.004)$ less reduced colon length $(12.1 \mathrm{~cm}[8.5-14.4 \mathrm{~cm}])$ as compared to controls (11.2 cm [9.8-12.3]), indicating less inflammation (Fig. 2). 

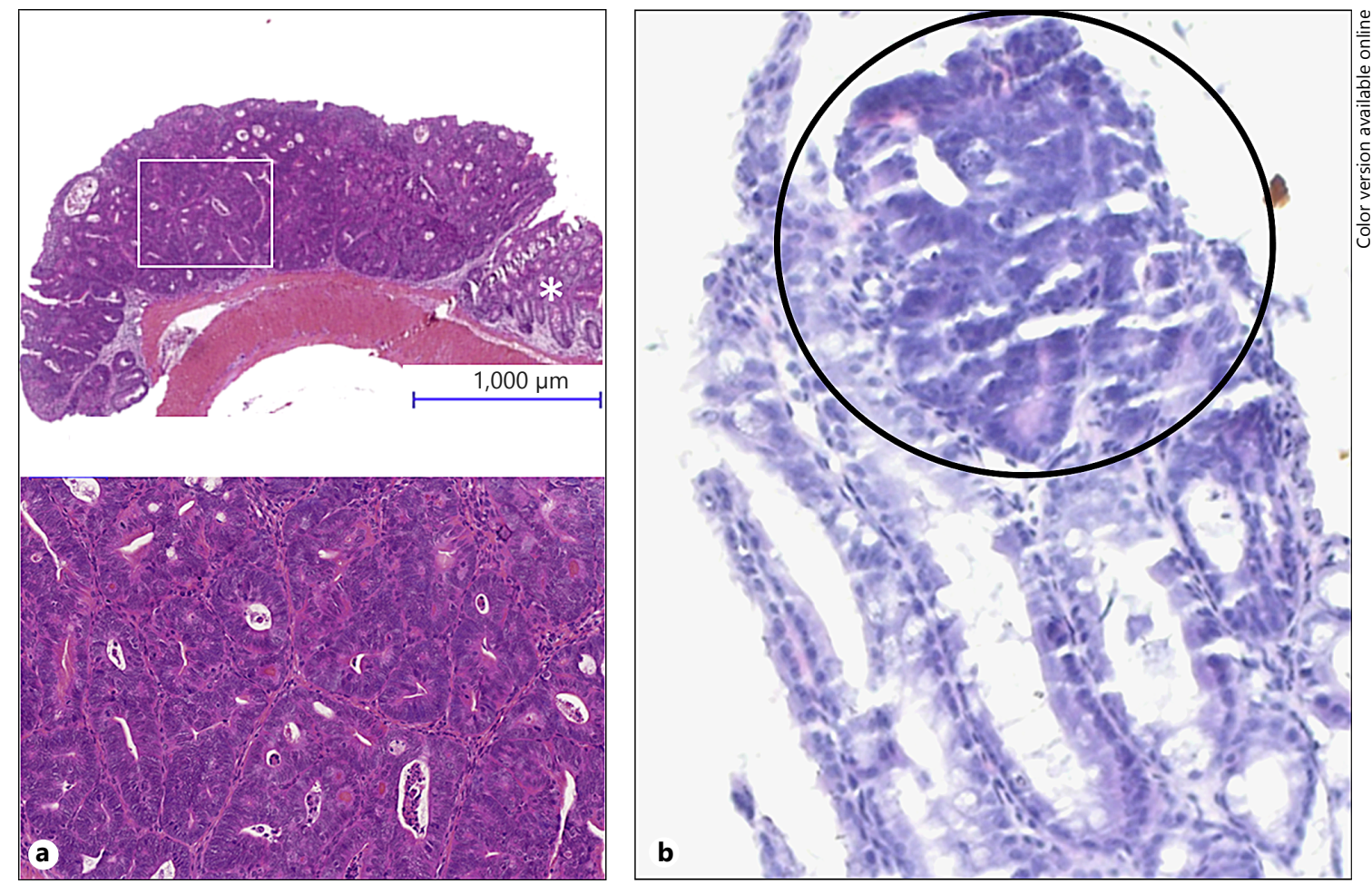

Fig. 1. a Histology confirmed the development of intraepithelial neoplasia for all groups. There was no difference with respect to low-grade or high-grade dysplasia (LG-IEN/HG-IEN). Dysplasia-

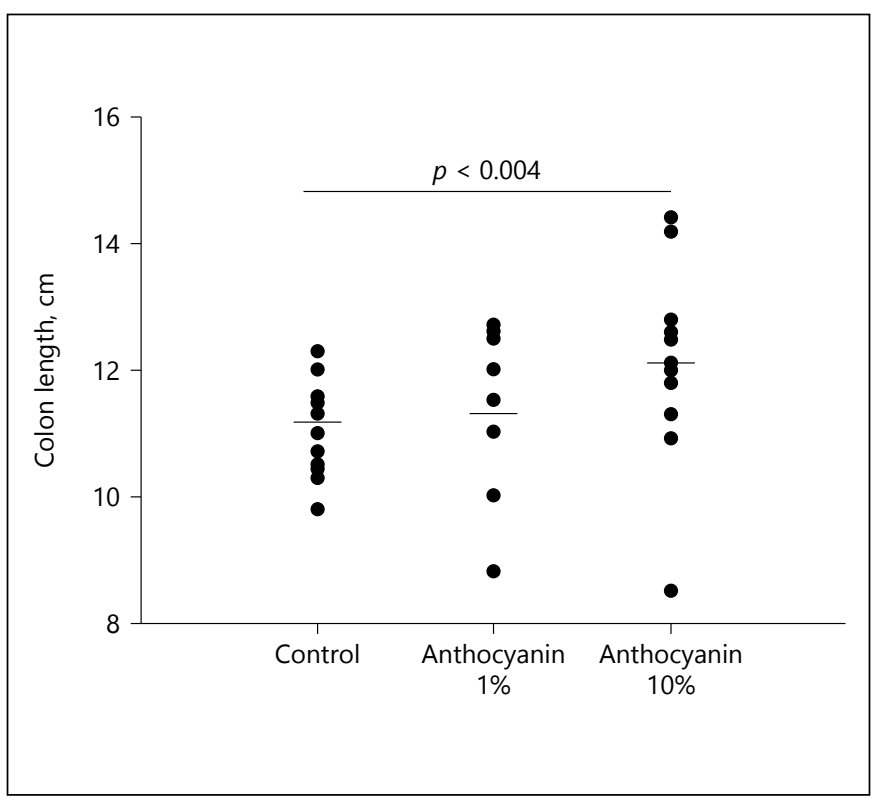

Fig. 2. The colon length as a sign of inflammation was significantly enlarged in the $10 \%$ anthocyanin group indicating less inflammation compared to the control group. associated invasive carcinoma was not observed. b Biopsy sampling of a tumour during endoscopy confirmed high-grade intraepithelial neoplasia.

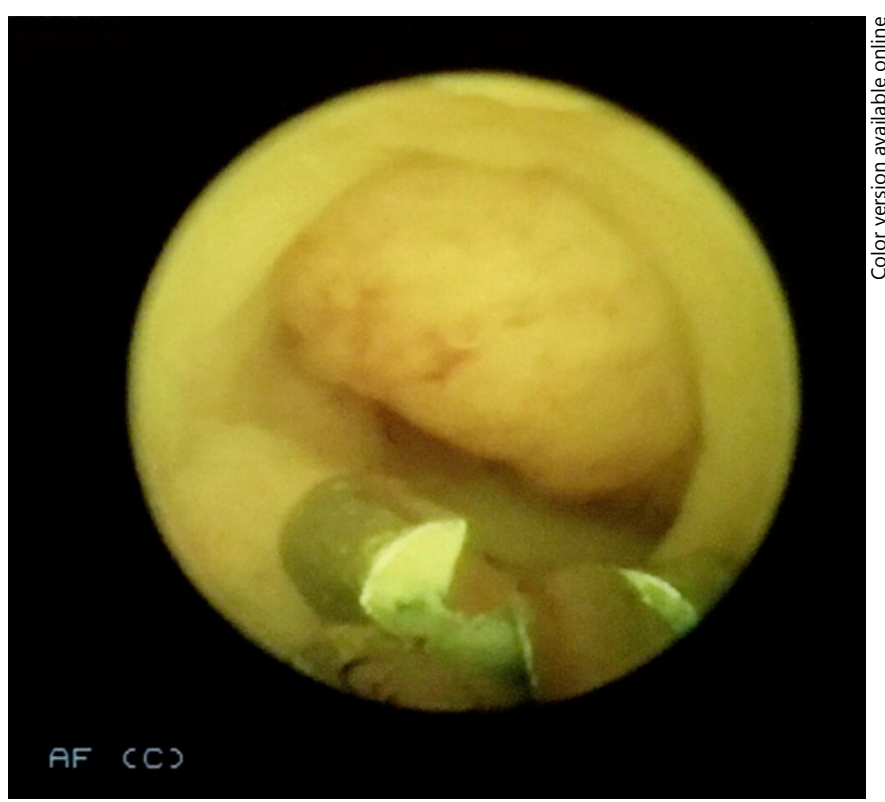

Fig. 3. In vivo high resolution endoscopy of a tumour up to a half of the colonic circumference and additional biopsy forceps. 


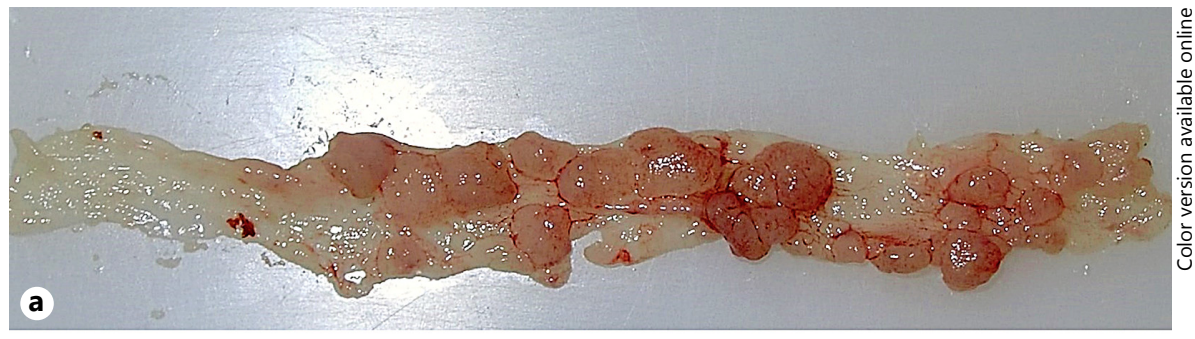

Fig. 4. Anthocyanin-treated mice show less tumours macroscopically compared to the control group. Exemplarily, one colon of each group at the end of the experiment is shown (a control group, b anthocyanin 1\%, c anthocyanin $10 \%)$.
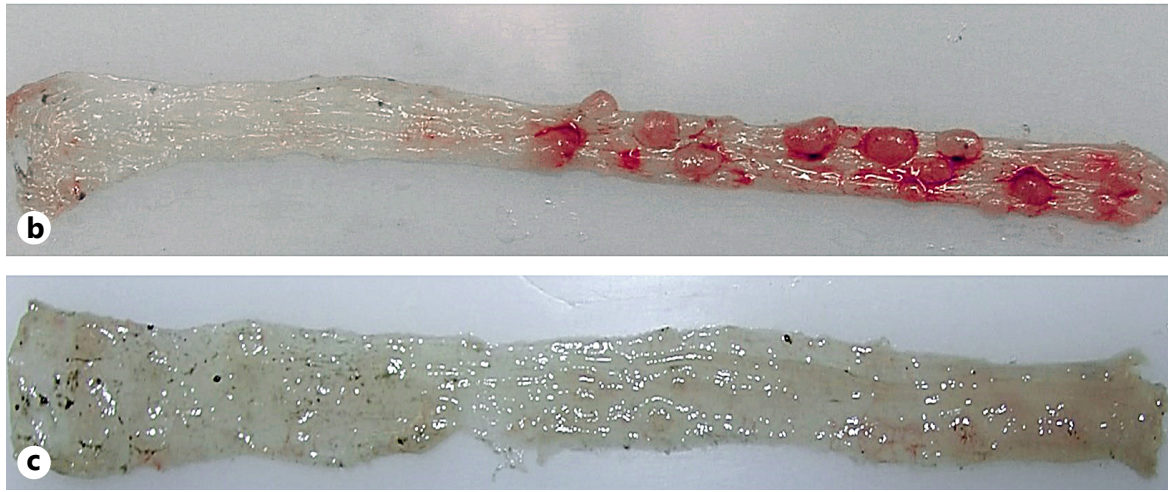

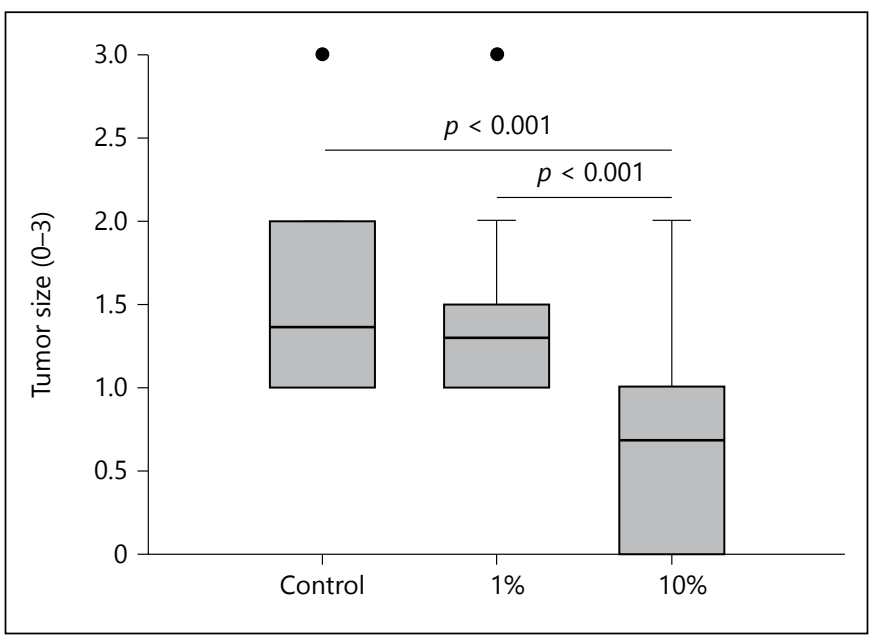

Fig. 5. Tumour sizes were evaluated for all groups. Mice fed with anthocyanins $10 \%$ revealed significantly less tumours compared to both control and anthocyanin $1 \%$ treated mice.

\section{Anthocyanin-Treated Mice Have Macroscopically Less} Tumours in the Colon

The number and size of tumours were evaluated macroscopically by colonoscopy at weeks 4 and 9 by 2 independent investigators. A total of 50 mice were included. One mouse from the $10 \%$ anthocyanin treatment group died during endoscopy. Control mice had no normal mucosa that were detectable during endoscopy, while in $1 \%$ treated mice, tumours were macroscopically less in number and size. The $10 \%$ treated mice had macroscopically almost no tumours that were detectable. Figure 3 shows a representative endoscopic picture of a tumour covering up to a half of the colonic circumference with biopsy forceps.

Becker et al. [17] developed endoscopic tumour scoring based on the number and size of tumours. In our study, we could reconfirm this scoring system during endoscopic examination, but we evaluated the number and size of tumours in detail at the end of the experiment (Fig. 4a-c).

Figure 5 shows median numbers of tumours depending on the tumour size for each group. Mice fed with $10 \%$ anthocyanin-rich extract revealed significantly less mean tumour numbers $(n=1.2)$ compared to control $(n=14)$ and anthocyanin $1 \%$ treated mice $(n=10.6, p<$ $0.001)$.

\section{Discussion}

We studied the effect of dietary anthocyanins in an inflammation driven colorectal cancer mouse model. During the study period of 10 weeks, anthocyanin supplementation of the diet was followed by a smaller tumour size in $1 \%$ and dramatically less and smaller tumours in $10 \%$ anthocyanin-treated mice compared to the control 
group. In addition, the anthocyanin diet prevented inflammation-induced reduction of colon length in $10 \%$ anthocyanin-treated mice compared to control mice.

So far, the exact mechanisms of how anthocyanins can inhibit colorectal cancer development are not completely clear.

In our model of cancer, histology reveals the development of intraepithelial neoplasia in all macroscopically documented tumours. No carcinoma could be found. Therefore, one could speculate that the follow up time was probably too short.

In vitro, anthocyanin extracts have an inhibitory effect on cancer cell proliferation via p21 and Bax [21]. Anthocyanins were also able to inhibit cell growth and are an inducer of cell apoptosis in colon cancer cells by modulating DNA damage [22-24], inducing a cell cycle arrest [12, 25] or are responsible for demethylation of tumour suppressor genes [26].

The findings on the prevention of colonic inflammation induced by DSS are in line with earlier experiments of our lab where we could demonstrate that anthocyanins have anti-inflammatory properties and ameliorate DSSinduced chronic colitis [27]. In human monocytic THP-1 cells, bilberry extract reduced interferon- $\gamma$ (IFN- $\gamma$ )induced signal protein activation, pro-inflammatory gene expression and cytokine secretion, and enhanced tumor necrosis factor- $\alpha$ (TNF- $\alpha$ )-induced responses [28]. Even a recent study on biopsy samples of patients with ulcerative colitis treated with an oral anthocyanin-rich bilberry preparation during an open label clinical trial revealed reduced amounts of the proinflammatory cytokines IFN- $\gamma$ and TNF- $\alpha$ [29].

Anthocyanins have been reported to reduce both inflammation and tumour development via downregulation of proinflammatory enzymes and suppression of NF- $\kappa B$ or VCAM-1 on both mRNA and protein level [30]. In vivo, anthocyanins were also found to be protective by inducing a cell cycle arrest and having an anti-proliferative effect [25] similar to the so-far known in vitro findings.

A human pilot study of oral anthocyanins as chemoprevention in colorectal cancer used mirtocyan, a mixture of anthocyanins from bilberry extract. Thomasset et al. [31] showed a reduction in proliferation index by $7 \%$ and anthocyanin appearing in plasma, colorectal tissue and urine. Furthermore, anthocyanidins may possibly play a role as sensitizing agents in colorectal cancer therapy [32]. Cvorovic et al. [32] tested cytotoxicity of anthocyanidins in primary (Caco-2) and metastatic (LoVo and LoVo/ADR) colorectal cancer cell lines. They could demonstrate that anthocyanidins had a strong cytotoxic effect in the metastatic drug-resistant cell line (LoVo/ADR).

In conclusion, we could demonstrate a protective role of anthocyanins in the development of CRC. We showed that anthocyanins reduced colon cancer development in our model, indicating that both mechanisms (inflammation and cell growth) are simultaneously influenced by anthocyanins. Murine high resolution endoscopy enables monitoring colorectal carcinogenesis and the effects of anthocyanins on tumour development over a continuous period. Furthermore, colonic biopsies were suited for histological analysis.

However, further studies are warranted to clarify the exact mechanisms of how anthocyanins can contribute to the prevention of colon cancer in this new model of high resolution endoscopic system. In the future, biopsy samples could also be used for immunological and molecular analysis.

\section{Disclosure Statement}

There are no conflicts of interest for all authors.

\section{References}

1 Jemal A, Bray F, Center MM, Ferlay J, Ward E, Forman D: Global cancer statistics. CA Cancer J Clin 2011;61:69-90.

2 Ferlay J, Steliarova-Foucher E, Lortet-Tieulent J, Rosso S, Coebergh JW, Comber H, Forman D, Bray F: Cancer incidence and mortality patterns in Europe: estimates for 40 countries in 2012. Eur J Cancer 2013;49: 1374-1403.

3 http://globocan.iarc.fr/Pages/fact_sheets_ population.aspx.

4 Pox C, Aretz S, Bischoff SC, Graeven U, Hass M, Heussner P, Hohenberger W, Holstege A, Hubner J, Kolligs F, Kreis M, Lux P, Ockenga
J, Porschen R, Post S, Rahner N, ReinacherSchick A, Riemann JF, Sauer R, Sieg A, Scheppach W, Schmitt W, Schmoll HJ, Schulmann $\mathrm{K}$, Tannapfel A, Schmiegel W: [S3-guideline colorectal cancer version 1.0]. Z Gastroenterol 2013;51:753-854.

5 van Duijnhoven FJ, Bueno-de-Mesquita HB, Ferrari P, Jenab M, Boshuizen HC, Ros MM, Casagrande C, Tjonneland A, Olsen A, Over$\operatorname{vad} \mathrm{K}$, Thorlacius-Ussing O, Clavel-Chapelon F, Boutron-Ruault MC, Morois S, Kaaks R, Linseisen J, Boeing H, Nothlings U, Trichopoulou A, Trichopoulos D, Misirli G, Palli D, Sieri S, Panico S, Tumino R, Vineis P, Peeters
PH, van Gils CH, Ocke MC, Lund E, Engeset D, Skeie G, Suarez LR, Gonzalez CA, Sanchez MJ, Dorronsoro M, Navarro C, Barricarte A, Berglund G, Manjer J, Hallmans G, Palmqvist R, Bingham SA, Khaw KT, Key TJ, Allen NE, Boffetta P, Slimani N, Rinaldi S, Gallo V, Norat T, Riboli E: Fruit, vegetables, and colorectal cancer risk: the European Prospective Investigation into Cancer and Nutrition. Am J Clin Nutr 2009;89:1441-1452.

6 Johnson CM, Wei C, Ensor JE, Smolenski DJ, Amos CI, Levin B, Berry DA: Meta-analyses of colorectal cancer risk factors. Cancer Causes Control 2013;24:1207-1222. 
7 Luo WP, Fang YJ, Lu MS, Zhong X, Chen YM, Zhang CX: High consumption of vegetable and fruit colour groups is inversely associated with the risk of colorectal cancer: a case-control study. Br J Nutr 2015;113:1129-1138.

8 Wang LS, Stoner GD: Anthocyanins and their role in cancer prevention. Cancer Lett 2008; 269:281-290.

9 Zhao C, Giusti MM, Malik M, Moyer MP, Magnuson BA: Effects of commercial anthocyanin-rich extracts on colonic cancer and nontumorigenic colonic cell growth. J Agric Food Chem 2004;52:6122-6128.

10 Renis M, Calandra L, Scifo C, Tomasello B, Cardile V, Vanella L, Bei R, La Fauci L, Galvano F: Response of cell cycle/stress-related protein expression and DNA damage upon treatment of $\mathrm{CaCo} 2$ cells with anthocyanins. Br J Nutr 2008;100:27-35.

11 Jing P, Bomser JA, Schwartz SJ, He J, Magnuson BA, Giusti MM: Structure-function relationships of anthocyanins from various anthocyanin-rich extracts on the inhibition of colon cancer cell growth. J Agric Food Chem 2008;56:9391-9398.

12 Yun JM, Afaq F, Khan N, Mukhtar H: Delphinidin, an anthocyanidin in pigmented fruits and vegetables, induces apoptosis and cell cycle arrest in human colon cancer HCT116 cells. Mol Carcinog 2009;48:260-270.

13 Boivin D, Blanchette M, Barrette S, Moghrabi A, Beliveau R: Inhibition of cancer cell proliferation and suppression of TNF-induced activation of NFkappaB by edible berry juice. Anticancer Res 2007;27:937-948.

14 Bobe G, Wang B, Seeram NP, Nair MG Bourquin LD: Dietary anthocyanin-rich tart cherry extract inhibits intestinal tumorigenesis in APC(Min) mice fed suboptimal levels of sulindac. J Agric Food Chem 2006;54: 9322-9328.

15 Cooke D, Schwarz M, Boocock D, Winterhalter P, Steward WP, Gescher AJ, Marczylo TH: Effect of cyanidin-3-glucoside and an anthocyanin mixture from bilberry on adenoma development in the ApcMin mouse model of intestinal carcinogenesis - relationship with tissue anthocyanin levels. Int J Cancer 2006; 119:2213-2220.
16 Kang SY, Seeram NP, Nair MG, Bourquin LD: Tart cherry anthocyanins inhibit tumor development in Apc(Min) mice and reduce proliferation of human colon cancer cells. Cancer Lett 2003;194:13-19.

17 Becker C, Fantini MC, Wirtz S, Nikolaev A, Kiesslich R, Lehr HA, Galle PR, Neurath MF: In vivo imaging of colitis and colon cancer development in mice using high resolution chromoendoscopy. Gut 2005;54:950-954.

18 Landfried K, Bataille F, Rogler G, Brenmoehl J, Kosovac K, Wolff D, Hilgendorf I, Hahn J, Edinger $\mathrm{M}$, Hoffmann $\mathrm{P}$, Obermeier $\mathrm{F}$, Schoelmerich J, Andreesen R, Holler E: Recipient NOD2/CARD15 status affects cellular infiltrates in human intestinal graft-versushost disease. Clin Exp Immunol 2010;159: 87-92.

19 Obermeier F, Kojouharoff G, Hans W, Scholmerich J, Gross V, Falk W: Interferon-gamma (IFN-gamma)- and tumour necrosis factor (TNF)-induced nitric oxide as toxic effector molecule in chronic dextran sulphate sodium (DSS)-induced colitis in mice. Clin Exp Immunol 1999;116:238-245.

20 Hans W, Scholmerich J, Gross V, Falk W: The role of the resident intestinal flora in acute and chronic dextran sulfate sodium-induced colitis in mice. Eur J Gastroenterol Hepatol 2000;12:267-273.

21 Wu QK, Koponen JM, Mykkanen HM, Torronen AR: Berry phenolic extracts modulate the expression of p21(WAF1) and Bax but not Bcl-2 in HT-29 colon cancer cells. J Agric Food Chem 2007;55:1156-1163.

22 Yi W, Fischer J, Krewer G, Akoh CC: Phenolic compounds from blueberries can inhibit colon cancer cell proliferation and induce apoptosis. J Agric Food Chem 2005;53:7320-7329.

23 Hsu CP, Shih YT, Lin BR, Chiu CF, Lin CC: Inhibitory effect and mechanisms of an anthocyanins- and anthocyanidins-rich extract from purple-shoot tea on colorectal carcinoma cell proliferation. J Agric Food Chem 2012;60:3686-3692.

24 Esselen M, Fritz J, Hutter M, Teller N, Baechler S, Boettler U, Marczylo TH, Gescher AJ, Marko D: Anthocyanin-rich extracts suppress the DNA-damaging effects of topoisomerase poisons in human colon cancer cells. Mol Nutr Food Res 2011;55(suppl 1): S143-S153.
25 Lim S, Xu J, Kim J, Chen TY, Su X, Standard J, Carey E, Griffin J, Herndon B, Katz B, Tomich J, Wang W: Role of anthocyanin-enriched purple-fleshed sweet potato p40 in colorectal cancer prevention. Mol Nutr Food Res 2013;57:1908-1917.

26 Wang LS, Kuo CT, Cho SJ, Seguin C, Siddiqui J, Stoner K, Weng YI, Huang TH, Tichelaar J, Yearsley M, Stoner GD, Huang YW: Black raspberry-derived anthocyanins demethylate tumor suppressor genes through the inhibition of DNMT1 and DNMT3B in colon cancer cells. Nutr Cancer 2013;65:118-125.

27 Piberger H, Oehme A, Hofmann C, Dreiseitel A, Sand PG, Obermeier F, Schoelmerich J, Schreier P, Krammer G, Rogler G: Bilberries and their anthocyanins ameliorate experimental colitis. Mol Nutr Food Res 2011;55: 1724-1729.

28 Roth S, Spalinger MR, Muller I, Lang S, Rogler G, Scharl M: Bilberry-derived anthocyanins prevent IFN- $\gamma$-induced pro-inflammatory signalling and cytokine secretion in human THP-1 monocytic cells. Digestion 2014;90: 179-189.

29 Roth S, Spalinger MR, Gottier C, Biedermann L, Zeitz J, Lang S, Weber A, Rogler G, Scharl M: Bilberry-derived anthocyanins modulate cytokine expression in the intestine of patients with ulcerative colitis. PLoS One 2016; 11:e0154817.

30 Banerjee N, Kim H, Talcott S, Mertens-Talcott $S$ : Pomegranate polyphenolics suppressed azoxymethane-induced colorectal aberrant crypt foci and inflammation: possible role of miR-126/VCAM-1 and miR-126/PI3K/AKT/ mTOR. Carcinogenesis 2013;34:2814-2822.

31 Thomasset S, Berry DP, Cai H, West K, Marczylo TH, Marsden D, Brown K, Dennison A, Garcea G, Miller A, Hemingway D, Steward WP, Gescher AJ: Pilot study of oral anthocyanins for colorectal cancer chemoprevention. Cancer Prev Res (Phila) 2009;2:625633.

32 Cvorovic J, Tramer F, Granzotto M, Candussio L, Decorti G, Passamonti S: Oxidative stress-based cytotoxicity of delphinidin and cyanidin in colon cancer cells. Arch Biochem Biophys 2010;501:151-157. 